Check for updates

Cite this: RSC Med. Chem., 2021, 12 363

Received 10th September 2020, Accepted 28th October 2020

DOI: $10.1039 / \mathrm{d} 0 \mathrm{md} 00310 \mathrm{~g}$

rsc.li/medchem

\section{Discovery, affinity maturation and multimerization of small molecule ligands against human tyrosinase and tyrosinase-related protein $1 \uparrow$}

\author{
Marco Catalano, (D) $\ddagger^{\mathrm{a}}$ Gabriele Bassi,,$^{\mathrm{a}}$ Giulia Rotondi, ${ }^{\text {ab }}$ Lyna Khettabi, ${ }^{\mathrm{cd}}$ \\ Maria Dichiara, ${ }^{a}$ Patrizia Murer, ${ }^{a}$ Jörg Scheuermann, ${ }^{a}$ \\ Montserrat Soler-Lopez ${ }^{\mathrm{C}}$ and Dario Neri ${ }^{\star a}$
}

\begin{abstract}
Human tyrosinase (hTYR) and tyrosinase-related protein 1 (hTYRP1) are closely-related enzymes involved in the synthesis of melanin, which are selectively expressed in melanocytes and, in a pathological context, in melanoma lesions. We used a previously described tyrosinase inhibitor (ThiamidolTM) and DNA-encoded library technology for the discovery of novel hTYR and hTYRP1 ligands, that could be used as vehicles for melanoma targeting. Performing de novo selections with DNA-encoded libraries, we discovered novel ligands capable of binding to both hTYR and hTYRP1. More potent ligands were obtained by multimerizing ThiamidolTM moieties, leading to homotetrameric structures that avidly bound to melanoma cells, as revealed by flow cytometry. These findings suggest that melanoma lesions may, in the future, be targeted not only by monoclonal antibody reagents but also by small organic ligands.
\end{abstract}

\section{Introduction}

The majority of conventional cytotoxic agents used for cancer therapy do not preferentially localize to neoplastic lesions. ${ }^{1,2}$ This pharmacokinetic limitation contributes to undesired toxicity and prevents dose escalation to therapeutic regimens, that would be needed in order to achieve a durable therapeutic benefit.

One avenue for improving the therapeutic index of chemotherapeutic agents consists in coupling them to monoclonal antibodies, serving as selective delivery vehicles. There has been a substantial interest in the development of antibody-drug conjugates (ADCs) for the therapy of cancer..$^{3-6}$ Nine products [Mylotarg $^{\mathrm{TM}}$, Adcetris ${ }^{\mathrm{TM}}$, Kadcyla ${ }^{\mathrm{TM}}$, Besponsa $^{\mathrm{TM}}$, Polivy ${ }^{\mathrm{TM}}$, Padcev ${ }^{\mathrm{TM}}$, Trodelvy ${ }^{\mathrm{TM}}$, Enhertu ${ }^{\mathrm{TM}}$, Blenrep ${ }^{\mathrm{TM}}$ ] have gained marketing authorization for the treatment of different types of malignancies and various other ADCs are currently being tested in clinical trials. ${ }^{7,8}$

\footnotetext{
${ }^{a}$ Department of Chemistry and Applied Biosciences, Swiss Federal Institute of Technology (ETH Zürich), Vladimir-Prelog-Weg 4, CH-8093 Zürich, Switzerland. E-mail: dario.neri@pharma.ethz.ch

${ }^{b}$ Dipartimento di Chimica e Tecnologie del Farmaco, Sapienza University of Rome, P.le A. Moro 5, 00185 Rome, Italy

${ }^{c}$ Structural Biology Group, European Synchrotron Radiation Facility, 71 Avenue des Martyrs, 38000 Grenoble, France

${ }^{d}$ CNRS, DCM, Université Grenoble Alpes, 38000 Grenoble, France

$\dagger$ Electronic supplementary information (ESI) available: ESI including material and methods used in this work. See DOI: 10.1039/d0md00310g

$\$$ These authors equally contributed to this work.
}

However, the development of ADC products can be problematic, due to high costs-of-goods and to off-target toxicity, which can be severe. ${ }^{9,10}$ It is widely recognized that the therapeutic index of ADCs is typically much higher in rodent models of cancer compared to the situation in humans, but the reasons for these discrepancies are still not fully understood. ${ }^{11-13}$ The tumor-homing properties of anticancer antibodies are often better in mice compared to patients, which is due (in part) to the fact that highly vascularized and rapidly growing tumors are typically used in the experimental setting. ${ }^{14,15}$

Small organic ligands have been proposed as an alternative to antibodies for the delivery of cytotoxics to tumors. ${ }^{16-18}$ Small molecule-drug conjugates (SMDCs) can be produced inexpensively and in large quantities. Moreover, a recent comparative analysis of the two platforms has shown that SMDCs may accumulate more efficiently and more homogenously in tumors compared to ADCs (which are typically confined to the perivascular space), ${ }^{19,20}$ since small molecules extravasate more rapidly than antibodies. ${ }^{21,22}$ Interestingly, in a side-by-side comparison, ADCs and SMDCs exhibited a comparable performance in mouse models of cancer, even though the tumor uptake of the SMDC products was clearly superior. ${ }^{19}$

Until recently, the development of SMDCs has been limited by the availability of small organic ligands, specific to tumor-associated antigens. Folate derivatives, somatostatin analogues, as well as synthetic ligands to prostate-specific membrane antigen (PSMA) and carbonic anhydrase IX (CAIX), 
a
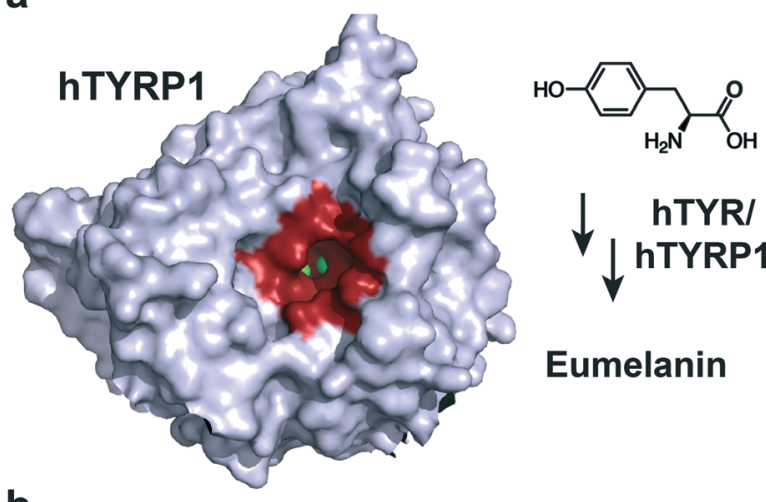

Eumelanin
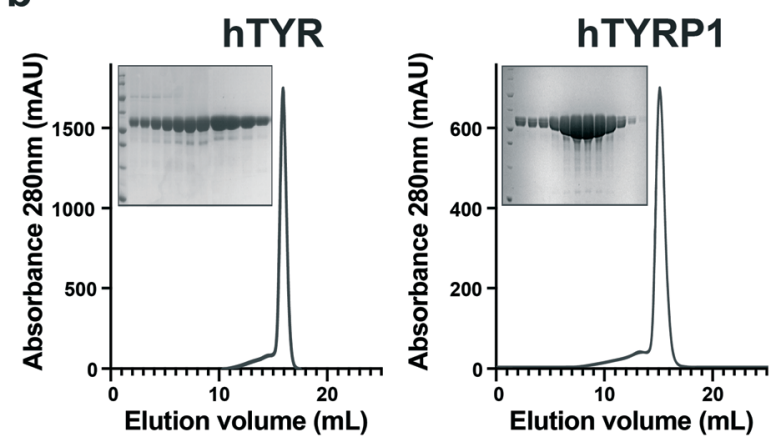

Fig. 1 Human tyrosinase (hTYR) and tyrosinase-related protein 1 (hTYRP1) are melanoma associated antigens that present favorable ligandability properties. a) Tyrosine is converted in eumelanin through the interaction with metal ions placed within the active site (depicted in red); b) chromatographic elution profiles of purified intra melanosomal human hTYR and hTYRP1 proteins. In the insets, SDSPAGE gels showing the purity of the eluted fractions in the peak volume. The first lane contains the MW marker, confirming the expected size of the proteins (PDB: 5M8P).

represent some of the small ligands, which have been shown to efficiently target tumors both in mouse models of cancer $^{23-27}$ and in patients. ${ }^{28-32}$ Further developments in the SMDC field will crucially rely on the availability of improved discovery technologies for small organic ligands. ${ }^{16}$

DNA-encoded chemical libraries (DELs) are collections of organic molecules, individually coupled to distinctive DNA fragments serving as amplifiable identification barcodes. ${ }^{33,34}$ DELs can be conveniently synthesized by split\&pool techniques, thus allowing the facile creation of libraries containing millions of compounds. ${ }^{35}$ Alternatively, the discovery of small binding peptides has been facilitated by the display on filamentous phage of chemically-modified bicyclic peptides ${ }^{36,37}$ or by ribosome display of cyclic peptides, containing unnatural amino acids. $^{38}$ The applications of these technologies for SMDC development have recently been reported. ${ }^{39-43}$

Human tyrosinase (hTYR) and tyrosinase-related protein 1 (hTYRP1) are closely-related enzymes, which are abundantly expressed in melanosomes and on the surface of melanoma cells. ${ }^{44,45}$ They are involved in the biosynthesis of melanin and are detectable in a very limited set of healthy tissues, such as skin, eyes and hairs. ${ }^{46,47}$ We hypothesized that ligands specific to hTYR and/or hTYRP1 could be ideally suited for tumor-targeting applications. TA99 is a monoclonal antibody specific to hTYRP1, which has been shown to selectively target melanoma and melanocytes in vivo. ${ }^{48} \mathrm{We}$ assumed that a small organic ligand, specific to hTYR or hTYRP1, might represent a valid alternative to TA99 for melanoma targeting applications.

In this article, we explored the possibility to generate hTYR and hTYRP1 ligands, that could be used for the selective recognition of melanoma cells. Our work was inspired by the recent discovery of Thiamidol ${ }^{\mathrm{TM}}$ (Beiersdorf $\mathrm{AG}$ ) as a tyrosinase inhibitor selective for the human version of the enzyme, leading to a product which has been approved for the treatment of irregular pigmentation of the skin. ${ }^{49-52}$ We studied whether a chemical modification of Thiamidol ${ }^{\mathrm{TM}}$ could be used for the selective delivery of chemical moieties to melanoma cells. We found that oligomerization of Thiamidol $^{\text {TM }}$ with dendrimeric scaffolds allowed the generation of novel multivalent ligands, capable of avid binding to melanoma cells. Moreover, we performed DEL selections against immobilized hTYRP1 and hTYR, yielding to novel chemotypes that are selectively enriched against both enzymes.

\section{Results and discussion}

\section{Binding properties of Thiamidol ${ }^{\mathrm{TM}}$ derivatives to hTYR and hTYRP1}

The structure of hTYRP1 has been elucidated by X-ray crystallography ${ }^{53}$ and has revealed the presence of a catalytic pocket, which could accommodate certain organic ligands, bearing structural analogies to tyrosine, the physiological substrate for melanin biosynthesis [Fig. 1a]. Pure preparations of recombinant hTYR and hTYRP1 were used in our studies, as revealed by size-exclusion chromatography and SDS-PAGE analysis [Fig. 1b].

We synthesized a terminal alkyne derivative of Thiamidol ${ }^{\mathrm{TM}}$, which could be suitable for Cu-catalyzed azidealkyne cycloaddition (CuAAC) coupling to azide-containing structures [Fig. 2]. The inhibitory potency of Thiamidol ${ }^{\mathrm{TM}}$ and Thiamidol ${ }^{\mathrm{TM}}$ alkyne was tested against human tyrosinase, using an enzymatic assay based on the production
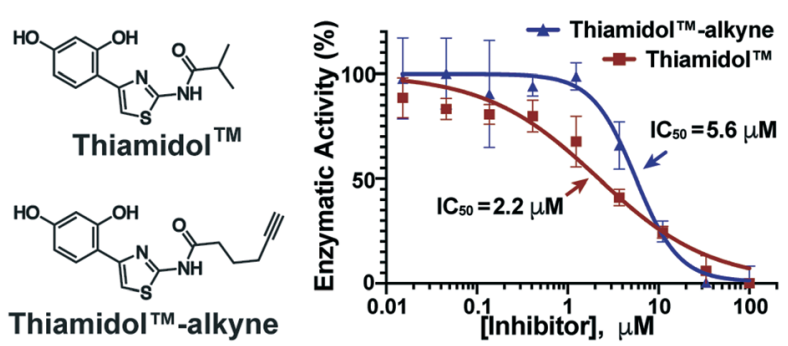

Fig. 2 A known hTYR inhibitor (ThiamidolTM) was modified with a derivatizable handle for later modifications. The new ThiamidolTM alkyne derivative retains the inhibitory capacity of the parent compound in presence of human hTYR. 
of L-DOPA and its subsequent conversion into a coloured adduct. $^{53,54}$ The experimental $\mathrm{IC}_{50}$ values for the two compounds were $2.2 \mu \mathrm{M}$ and $5.6 \mu \mathrm{M}$, respectively [Fig. 2]. These values are in keeping with previous measurements, performed on a series of thiazolyl-resorcinol variants. ${ }^{50}$

Discovery of novel hTYR and hTYRP1 binders from DEL libraries In order to perform DEL selections against hTYR and hTYRP1, the two enzymes were chemically biotinylated and used in affinity capture procedures on streptavidin-coated magnetic beads. We screened a DEL library recently described by our laboratory (termed GB-DEL), ${ }^{55}$ featuring the

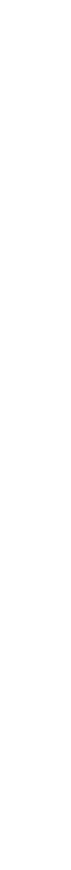

a
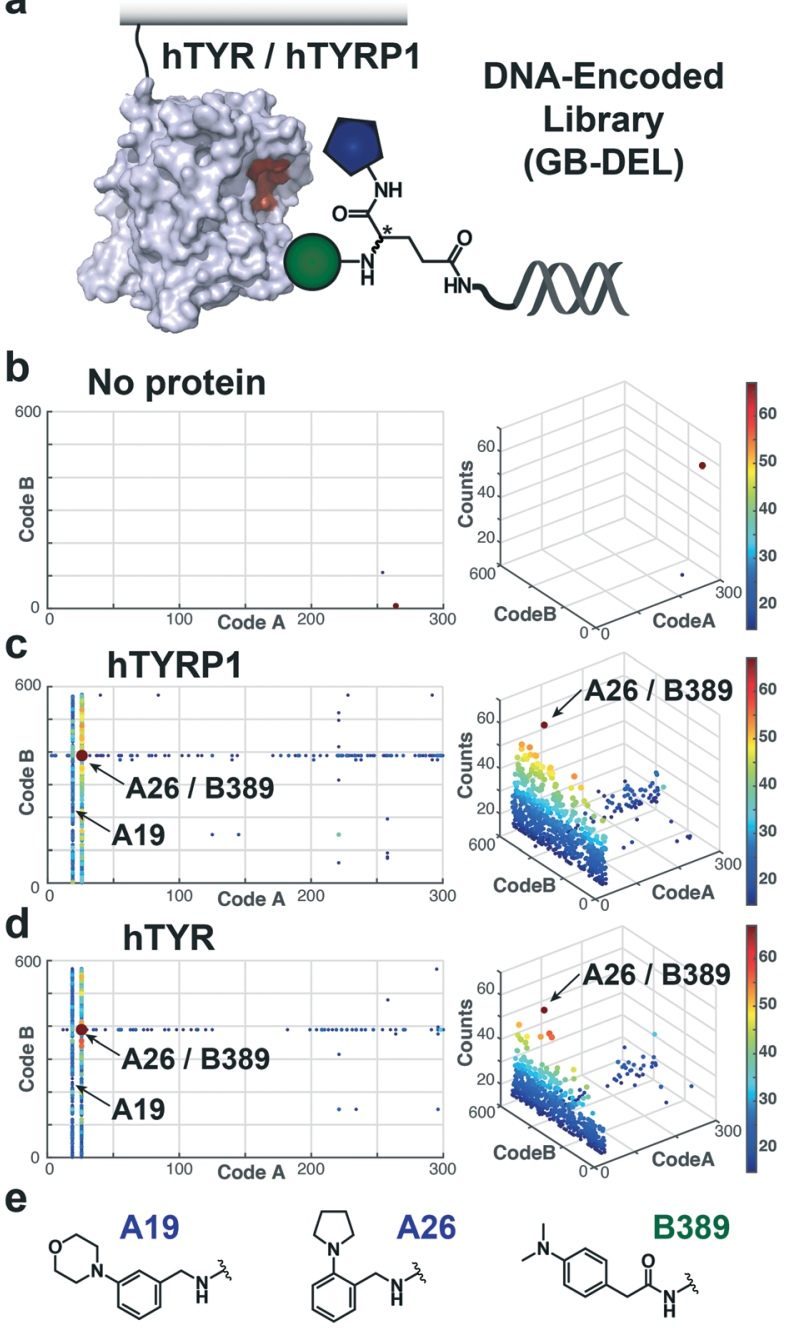

Fig. 3 Discovery of novel binding fragments for hTYR and hTYRP1 through DNA-encoded library (GB-DEL). a) A single-pharmacophore DEL, based on a racemic glutamic acid scaffold, was screened in presence of immobilized hTYR and hTYRP1 proteins; b-d) bi- and tri-dimensional plots of the resulting selections fingerprints after incubation with streptavidin coated beads, hTYRP1 and hTYR are reported. Selections against hTYR and hTYRP1 displayed A26/B389 as the most enriched combination of building blocks; e) the chemical structures of the enriched fragments are reported, whose binding affinities were evaluated through fluorescence polarization measurements in presence of hTYRP1 [Fig. S1†]. use of glutamic acid analogues for the combinatorial display of two sets of building blocks [Fig. 3a]. The library contained $366^{\prime} 600$ encoded compounds. Decoding of the library after capture on "empty" streptavidin-based supports using highthroughput DNA sequencing [Fig. 3b] revealed a homogeneous distribution of compounds, without striking enrichments of individual molecules. ${ }^{55}$ By contrast, selections performed on biotinylated hTYR or hTYRP1 on streptavidin-coated magnetic beads revealed a characteristic enrichment of "lines" of compounds, which in DEL
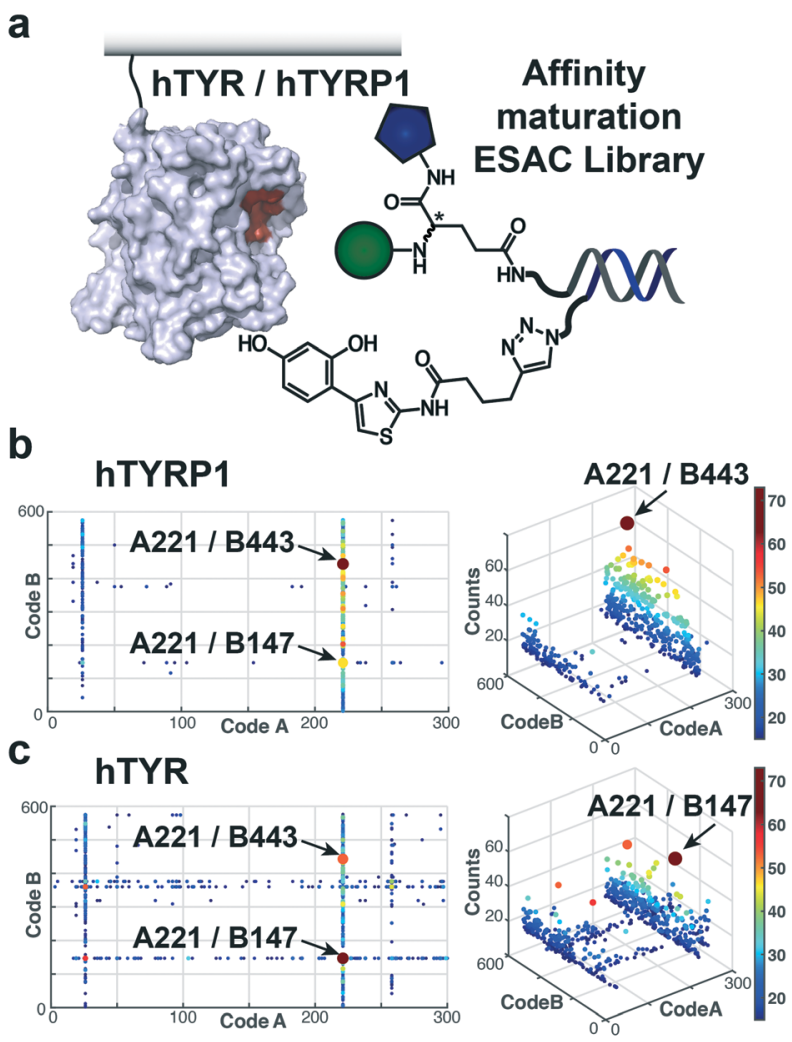

d

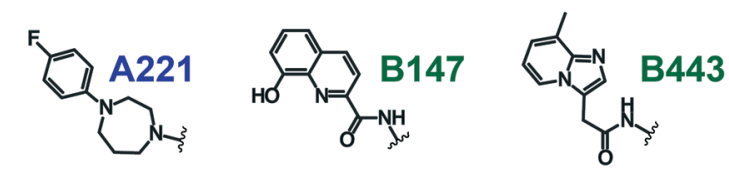

Fluorescence Polarization

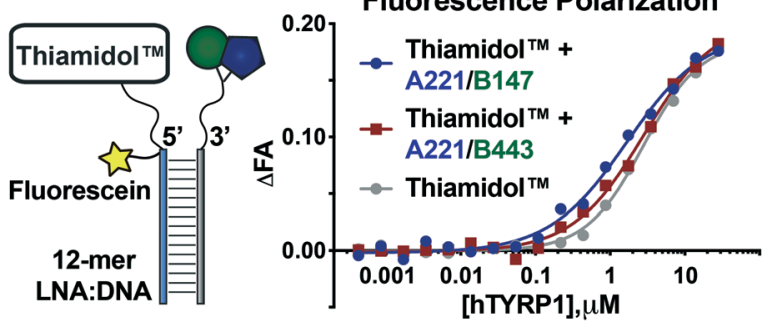

Fig. 4 ESAC-based affinity maturation of ThiamidolTM ligand. a) The single-stranded GB-DEL library was paired with a complementary DNAfragment displaying a Thiamidol ${ }^{\mathrm{TM}}$ derivative and screened in presence of hTYR and hTYRP1; b and c) decoding plots of the selection experiment delineate fragments particularly enriched upon incubation with hTYRP1 and hTYR; d) DNA-linked fragments were paired to fluoresceinated LNAscaffolds presenting a ThiamidolTM derivative. Binding affinities towards hTYRP1 were measured through fluorescence polarization. 
technology is typically indicative of preferential binding by the corresponding building blocks [Fig. $3 \mathrm{c}$ and $\mathrm{d}$ ]. In particular, we observed an enrichment for building blocks A19, A26 and B389, whose structures are depicted in Fig. 3e. They all include tri-alkylated amine moieties in the chemical structure, resembling chemical features showed by previously described melanoma-targeting agents. ${ }^{56,57}$ The simultaneous selection of these building blocks on both hTYR and hTYRP1 may reflect the conservation of the active site of the two enzymes, in spite of the fact that total amino acid sequence homology was only $40 \% .^{58}$ The compounds were resynthesized as fluorescein conjugates and tested for binding in fluorescence polarization, exhibiting binding potency in the micromolar concentration range [ESI $\uparrow$ Fig. S1]. Scarce binding affinities were also detected upon enzymatic assay in the presence of hTYR [ESI $\dagger$ Fig. S2 and S3]. We also performed DEL selections in encoded self-assembling chemical (ESAC) library format, pairing the GB-DEL library with a complementary DNA strand, equipped with a Thiamidol $^{\mathrm{TM}}$ moiety [Fig. 4a]. Also in this case, a characteristic enrichment of lines of compounds was observed, that corresponded to building blocks A221, B147 and B443 [Fig. 4b and c]. Bidentate ligands were produced and tested on a fluoresceinated DNA scaffold using previously described procedures. ${ }^{59-61}$ Surprisingly, the combination of Thiamidol $^{\text {TM }}$ with A221/B147 and A221/B443 did not substantially improve binding performance in fluorescence polarization studies [Fig. 4d].

\section{Targeting melanoma cells with oligomeric derivatives of Thiamidol ${ }^{\mathrm{TM}}$}

Ligands for transmembrane antigens can be constructed on multimeric scaffolds to achieve better targeting performance, by means of avidity. Avid interactions can improve the total affinity of multimeric ligands, yielding to longer residency time on cancer cells and therefore better anticancer outcomes. $^{62,63}$ We conjugated the alkyne derivative of Thiamidol $^{\mathrm{TM}}$ (Thiamidol $^{\mathrm{TM}}$ alkyne) on azide-containing scaffolds, obtaining monomeric, dimeric and tetrameric structures [Fig. 5]. The peptidic scaffold included a charged aminoacidic triad (Asp-Arg-Asp) to improve solubility and to confine the ligand in the extracellular space. The terminal cysteine was found particularly convenient, enabling the easy conjugation of fluorescein-5-maleimide reagent.

We measured the affinity in solution of oligomeric Thiamidol ${ }^{\mathrm{TM}}$ based ligands using a recently described ELISA assay on hTYR and hTYRP1 coated wells. ${ }^{64}$ Both dimeric and tetrameric ligands significantly improved the affinity towards hTYR and hTYRP1, in comparison to an analogue monomeric
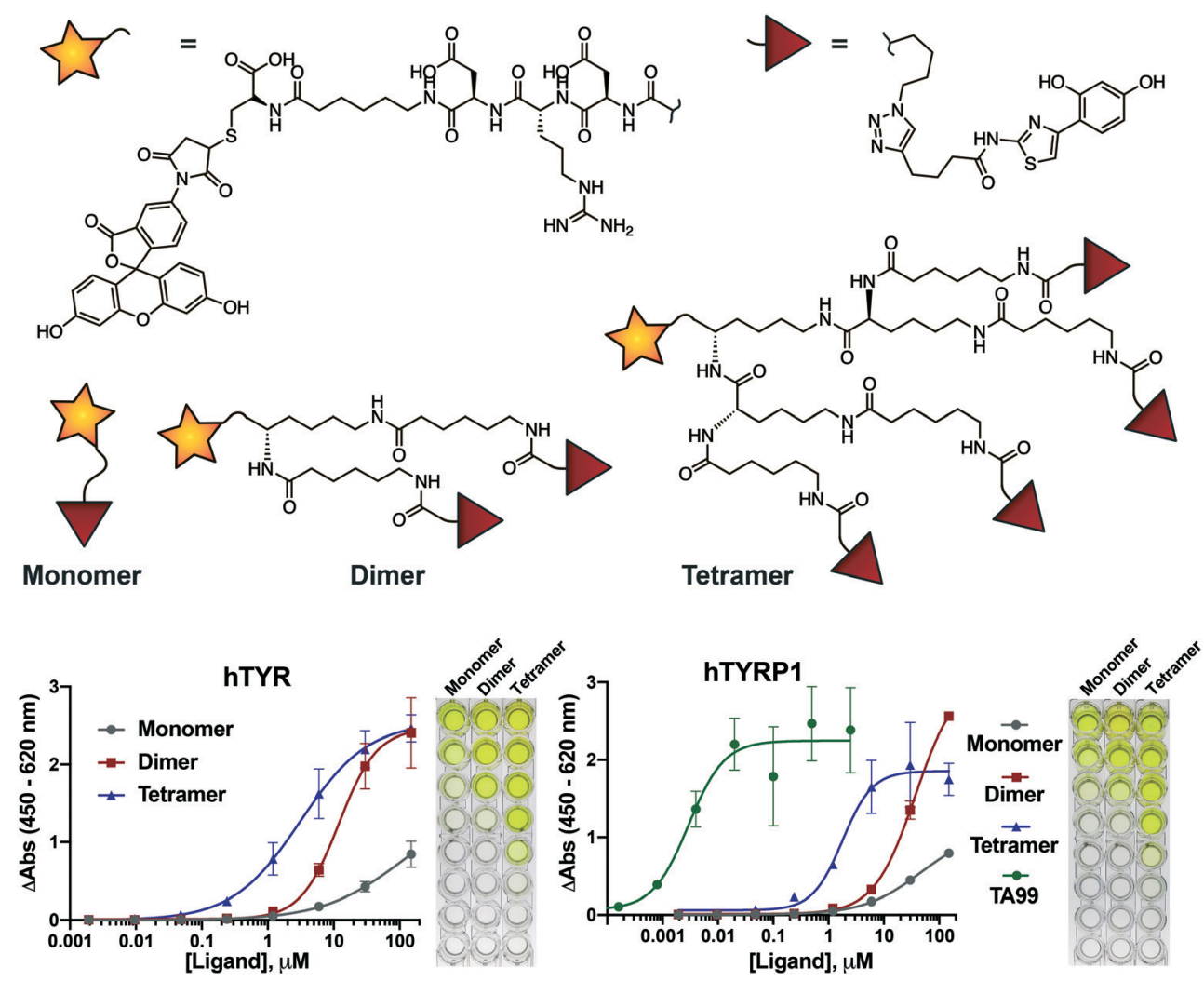

Fig. 5 ThiamidolTM alkyne was conjugated to multimeric scaffolds in order to achieve ligands with different binding avidities. The peptidic linker composed by the triad Asp-Arg-Asp was conjugated to fluorescein and to Thiamidol ${ }^{\mathrm{TM}}$ derivative through three scaffolds with different valences (i.e., monomeric, dimeric and tetrameric). Binding affinities of monomer, dimer and tetramer were evaluated through ELISA assay on hTYR and hTYRP1 coated microtiter wells. 

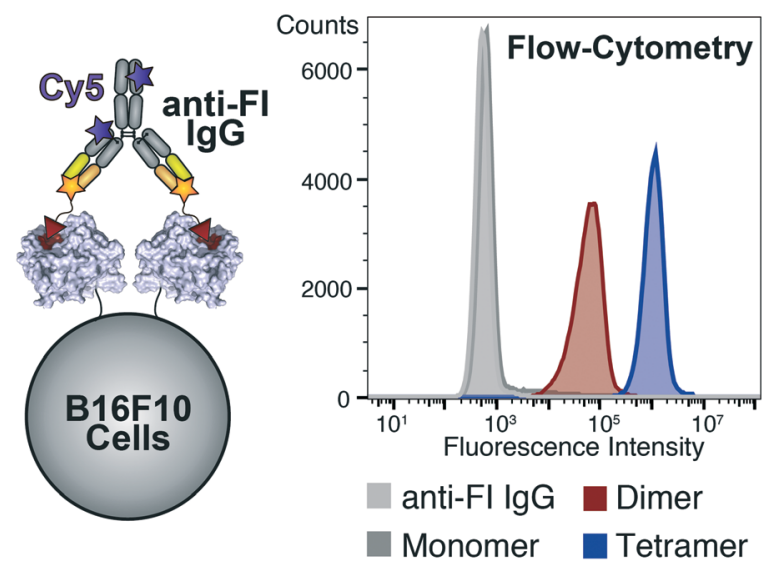

Fig. 6 Binding properties of Thiamidol ${ }^{\mathrm{TM}}$ based fluorescein-labelled ligands were evaluated in presence of B16F10 melanoma cells. Cells were incubated with a fixed concentration of ligands $(1 \mu \mathrm{M})$ and the residual binding was detected by flow-cytometry. An anti-fluorescein antibody labelled with Cy5-dye was employed to enhance signal intensity and reduce autofluorescence background.

structure [Fig. 5]. The tetrameric structure yielded to the strongest binding interaction with both proteins, reaching single-digit micromolar affinity. However, this affinity is yet ca. 1000-fold worse than the anti-TYRP1 antibody (TA99), which reacts to both human and murine antigen. ${ }^{65}$

We further validated ligands' binding properties in presence of melanoma cells, expressing hTYR and hTYRP1 proteins (i.e., B16F10). Melanoma cells were incubated with fluorescein-labelled ligands, washed from non-binding excess and stained with an anti-fluorescein antibody labelled with Cy5-fluorophore [Fig. 6]. The fluorescence signal was detected by flow-cytometry, clearly indicating the tetramer as the best binding ligand on B16F10 cells compared to the analogue dimer and monomer.

\section{Discussion}

The development of high affinity small molecule ligands for the human version of tyrosinase and tyrosinase-related protein 1 may result to novel targeting agents for the treatment of melanoma. Here we presented the use of DEL-technology for the discovery of such ligands, yielding to selective enrichment of fragments in the presence of both hTYR and hTYRP1. Additionally, the single-stranded version of a DEL-library (GB DEL) was employed for the affinity maturation of Thiamidol ${ }^{\mathrm{TM}}$, obtaining also in this case promising fingerprints. Surprisingly, a significant discrepancy between screening results and binding affinities was detected, highlighting the necessity of DELselection experiments that better recapitulate the strength of the molecular interaction with sequence enrichment. We also investigated the use of multimeric Thiamidol ${ }^{\mathrm{TM}}$ derivatives to stabilize the binding interaction between the inhibitor and its cognate proteins (hTYR and hTYRP1). Although the tetrametric structure displayed $c a$. 100-fold affinity enhancement compared to the analogue monomeric ligand, yet the strength of the interaction remains much weaker compared to the one of the TA99 antibody. Furthermore, the conjugation of second moieties to Thiamidol ${ }^{\mathrm{TM}}$ resulted in an apparent loss of binding affinity, which may impair further developments of Thiamidol ${ }^{\mathrm{TM}}$ based conjugates. This work represents a starting point for the development of higher affinity organic ligands of hTYR and/or hTYRP1 that can eventually become a novel targeted treatment against melanoma.

\section{Conclusions}

Collectively, our study suggests that Thiamidol ${ }^{\mathrm{TM}}$ derivatives (or more in general hTYR and hTYRP1 binders) may be considered for pharmacodelivery strategies against melanoma. Similar to antibodies, multivalence plays a role in strengthening binding interactions against protein targets, expressed at high density on tumor cells. We anticipate that SMDCs directed against hTYR and/or hTYRP1 may be particularly suited for the treatment of melanoma, as the cognate antigens exhibit an extremely restricted pattern of expression in normal tissues, mainly confined to few melanocyte cells in the skin. ${ }^{47,66} \mathrm{~A}$ radiolabelled derivative of an anti-melanin antibody has previously been proposed for melanoma treatment $t^{67,68}$ but, to the best of our knowledge, anti-melanoma ADC products have not yet been developed. Intact antibodies to hTYRP1 may be suitable for prevention of metastatic spread, ${ }^{66,69}$ but are not sufficiently potent for the eradication of established melanoma lesions. The discovery of more potent ligands specific to the human version of tyrosinase and tyrosinase-related protein 1 will be crucially important for the development of efficacious SMDC therapeutics. ${ }^{70}$

\section{Contributions}

M. C. and D. N. designed the project and the experiments. M. S. L. and L. K. provided recombinant human hTYR and hTYRP1. G. B. synthesized GB-DEL library and performed DEL-screening. M. C. and J. S. evaluated HTS data. M. C. and G. B. performed on-DNA synthesis and measurements. M. C., G. R. and M. D. synthesized off-DNA compounds. M. C. and G. R. performed binding and activity assays. M. C., G. R. and P. M. performed FACS analysis. All authors gave approval to the final version of the manuscript.

\section{Conflicts of interest}

The authors declare the following competing financial interest(s): D. N. is a cofounder and shareholder of Philochem AG.

\section{Acknowledgements}

The authors gratefully acknowledge financial support from ETH Zürich, the Swiss National Science Foundation (Grant Nr. 310030B_182003/1) and European Research Council (ERC) under the European Union's Horizon 2020 research and innovation program (grant agreement 670603). L. K. 
acknowledges funding support from the IDEX University Grenoble Alpes project (ANR-15-IDEX-02) under grant agreement C7H-ID17-P22-COSMRH.

\section{Notes and references}

1 A. A. M. van der Veldt, N. H. Hendrikse, E. F. Smit, M. P. J. Mooijer, A. Y. Rijnders, W. R. Gerritsen, J. J. M. van der Hoeven, A. D. Windhorst, A. A. Lammertsma and M. Lubberink, Eur. J. Nucl. Med. Mol. Imaging, 2010, 37, 1950-1958.

2 A. A. M. van der Veldt, M. Lubberink, R. H. J. Mathijssen, W. J. Loos, G. J. M. Herder, H. N. Greuter, E. F. I. Comans, H. B. Rutten, J. Eriksson, A. D. Windhorst, N. H. Hendrikse, P. E. Postmus, E. F. Smit and A. A. Lammertsma, Clin. Cancer Res., 2013, 19, 4163-4173.

3 A. Beck, L. Goetsch, C. Dumontet and N. Corvaïa, Nat. Rev. Drug Discovery, 2017, 16, 315-337.

4 A. Thomas, B. A. Teicher and R. Hassan, Lancet Oncol., 2016, 17, e254-e262.

5 M. J. Birrer, K. N. Moore, I. Betella and R. C. Bates, JNCI, J. Natl. Cancer Inst., 2019, 111, 538-549.

6 C. H. Chau, P. S. Steeg and W. D. Figg, Lancet, 2019, 394, 793-804.

7 P. Zhao, Y. Zhang, W. Li, C. Jeanty, G. Xiang and Y. Dong, Acta Pharm. Sin. B, 2020, 10(9), 1589-1600.

8 A. Bardia, I. A. Mayer, L. T. Vahdat, S. M. Tolaney, S. J. Isakoff, J. R. Diamond, J. O'Shaughnessy, R. L. Moroose, A. D. Santin, V. G. Abramson, N. C. Shah, H. S. Rugo, D. M. Goldenberg, A. M. Sweidan, R. Iannone, S. Washkowitz, R. M. Sharkey, W. A. Wegener and K. Kalinsky, N. Engl. J. Med., 2019, 380, 741-751.

9 R. S. Zolot, S. Basu and R. P. Million, Nat. Rev. Drug Discovery, 2013, 12, 259-260.

10 A. W. Tolcher, Ann. Oncol., 2016, 27, 2168-2172.

11 E. Khera and G. M. Thurber, BioDrugs, 2018, 32, 465-480.

12 S. Coats, M. Williams, B. Kebble, R. Dixit, L. Tseng, N.-S. Yao, D. A. Tice and J.-C. Soria, Clin. Cancer Res., 2019, 25, 5441-5448.

13 M. Vankemmelbeke and L. Durrant, Ther. Delivery, 2016, 7, 141-144.

14 M. de Jong and T. Maina, J. Nucl. Med., 2010, 51, 501-504.

15 C.-P. Day, G. Merlino and T. Van Dyke, Cell, 2015, 163, 39-53.

16 N. Krall, J. Scheuermann and D. Neri, Angew. Chem., Int. Ed., 2013, 52, 1384-1402.

17 M. Srinivasarao, C. V. Galliford and P. S. Low, Nat. Rev. Drug Discovery, 2015, 14, 203-219.

18 M. Srinivasarao and P. S. Low, Chem. Rev., 2017, 117, 12133-12164.

19 S. Cazzamalli, A. Dal Corso, F. Widmayer and D. Neri, J. Am. Chem. Soc., 2018, 140, 1617-1621.

20 M. S. Dennis, H. Jin, D. Dugger, R. Yang, L. McFarland, A. Ogasawara, S. Williams, M. J. Cole, S. Ross and R. Schwall, Cancer Res., 2007, 67, 254-261.

21 G. M. Thurber and R. Weissleder, PLoS One, 2011, 6, e24696.
22 G. M. Thurber and R. Weissleder, Mol. Imaging Biol., 2011, 13, 623-632.

23 C. J. Mathias, S. Wang, D. J. Waters, J. J. Turek, P. S. Low and M. A. Green, J. Nucl. Med., 1998, 39, 1579-1585.

24 M. de Jong, R. Valkema, F. Jamar, L. K. Kvols, D. J. Kwekkeboom, W. A. P. Breeman, W. H. Bakker, C. Smith, S. Pauwels and E. P. Krenning, Semin. Nucl. Med., 2002, 32, 133-140.

25 M. Ginj, H. Zhang, B. Waser, R. Cescato, D. Wild, X. Wang, J. Erchegyi, J. Rivier, H. R. Macke and J. C. Reubi, Proc. Natl. Acad. Sci. U. S. A., 2006, 103, 16436-16441.

26 S. M. Hillier, K. P. Maresca, G. Lu, R. D. Merkin, J. C. Marquis, C. N. Zimmerman, W. C. Eckelman, J. L. Joyal and J. W. Babich, J. Nucl. Med., 2013, 54, 1369-1376.

27 N. Krall, F. Pretto, W. Decurtins, G. J. Bernardes, C. T. Supuran and D. Neri, Angew. Chem., Int. Ed., 2014, 53, 4231-4235.

28 G. M. van Dam, G. Themelis, L. M. A. Crane, N. J. Harlaar, R. G. Pleijhuis, W. Kelder, A. Sarantopoulos, J. S. de Jong, H. J. G. Arts, A. G. J. van der Zee, J. Bart, P. S. Low and V. Ntziachristos, Nat. Med., 2011, 17, 1315-1319.

29 P. S. Low, W. A. Henne and D. D. Doorneweerd, Acc. Chem. Res., 2008, 41, 120-129.

30 Y. Xia, C. Zeng, Y. Zhao, X. Zhang, Z. Li and Y. Chen, EJNMMI Res., 2020, 10, 36.

31 J. A. Barrett, R. E. Coleman, S. J. Goldsmith, S. Vallabhajosula, N. A. Petry, S. Cho, T. Armor, J. B. Stubbs, K. P. Maresca, M. G. Stabin, J. L. Joyal, W. C. Eckelman and J. W. Babich, J. Nucl. Med., 2013, 54, 380-387.

32 O. C. Kulterer, S. Pfaff, W. Wadsak, N. Garstka, M. Remzi, C. Vraka, L. Nics, F. Bootz, S. Cazzamalli, N. Krall, D. Neri and A. R. Haug, J. Nucl. Med., 2020, DOI: 10.2967/jnumed.120.245530.

33 R. A. Goodnow, C. E. Dumelin and A. D. Keefe, Nat. Rev. Drug Discovery, 2017, 16, 131-147.

34 N. Favalli, G. Bassi, J. Scheuermann and D. Neri, FEBS Lett., 2018, 592, 2168-2180.

35 D. Neri and R. A. Lerner, Annu. Rev. Biochem., 2018, 87, 479-502.

36 S. Chen and C. Heinis, Methods Mol. Biol., 2015, 1248, 119-137.

37 C. A. Rhodes and D. Pei, Chem. - Eur. J., 2017, 23, 12690-12703.

38 J. Ottl, L. Leder, J. V. Schaefer and C. E. Dumelin, Molecules, 2019, 24, 1629.

39 M. Wichert, N. Krall, W. Decurtins, R. M. Franzini, F. Pretto, P. Schneider, D. Neri and J. Scheuermann, Nat. Chem., 2015, 7, 241-249.

40 S. Cazzamalli, B. Ziffels, F. Widmayer, P. Murer, G. Pellegrini, F. Pretto, S. Wulhfard and D. Neri, Clin. Cancer Res., 2018, 24, 3656-3667.

41 G. E. Mudd, A. Brown, L. Chen, K. van Rietschoten, S. Watcham, D. P. Teufel, S. Pavan, R. Lani, P. Huxley and G. S. Bennett, J. Med. Chem., 2020, 63, 4107-4116.

42 K. Iwasaki, Y. Goto, T. Katoh, T. Yamashita, S. Kaneko and H. Suga, J. Mol. Evol., 2015, 81, 210-217.

43 P. Hoppenz, S. Els-Heindl and A. G. Beck-Sickinger, Front. Chem., 2020, 8, 571. 
44 S. D'Mello, G. Finlay, B. Baguley and M. Askarian-Amiri, Int. J. Mol. Sci., 2016, 17, 1144.

45 A. N. Houghton, M. Eisinger, A. P. Albino, J. G. Cairncross and L. J. Old, J. Exp. Med., 1982, 156, 1755-1766.

46 X. Lai, H. J. Wichers, M. Soler-Lopez and B. W. Dijkstra, Chem. - Eur. J., 2018, 24, 47-55.

47 M. Uhlen, L. Fagerberg, B. M. Hallstrom, C. Lindskog, P. Oksvold, A. Mardinoglu, A. Sivertsson, C. Kampf, E. Sjostedt, A. Asplund, I. Olsson, K. Edlund, E. Lundberg, S. Navani, C. A.-K. Szigyarto, J. Odeberg, D. Djureinovic, J. O. Takanen, S. Hober, T. Alm, P.-H. Edqvist, H. Berling, H. Tegel, J. Mulder, J. Rockberg, P. Nilsson, J. M. Schwenk, M. Hamsten, K. von Feilitzen, M. Forsberg, L. Persson, F. Johansson, M. Zwahlen, G. von Heijne, J. Nielsen and F. Ponten, Science, 2015, 347, 1260419.

48 Y. M. Saenger, Y. Li, K. C. Chiou, B. Chan, G. Rizzuto, S. L. Terzulli, T. Merghoub, A. N. Houghton and J. D. Wolchok, Cancer Res., 2008, 68, 9884-9891.

49 T. Mann, W. Gerwat, J. Batzer, K. Eggers, C. Scherner, H. Wenck, F. Stab, V. J. Hearing, K. H. Rohm and L. Kolbe, J. Invest. Dermatol., 2018, 138, 1601-1608.

50 T. Mann, C. Scherner, K.-H. Röhm and L. Kolbe, Int. J. Mol. Sci., 2018, 19, 690.

51 C. Arrowitz, A. M. Schoelermann, T. Mann, L. I. Jiang, T. Weber and L. Kolbe, J. Invest. Dermatol., 2019, 139, 1691-1698.e6.

52 W. G. Philipp-Dormston, A. Vila Echagüe, S. H. Pérez Damonte, J. Riedel, A. Filbry, K. Warnke, C. Lofrano, D. Roggenkamp and G. Nippel, Int. J. Cosmet. Sci., 2020, 42, 377-387.

53 X. Lai, H. J. Wichers, M. Soler-Lopez and B. W. Dijkstra, Angew. Chem., Int. Ed., 2017, 56, 9812-9815.

54 A. J. Winder and H. Harris, Eur. J. Biochem., 1991, 198, 317-326.

55 G. Bassi, N. Favalli, M. Vuk, M. Catalano, A. Martinelli, A. Trenner, A. Porro, S. Yang, C. L. Tham, M. Moroglu, W. W. Yue, S. J. Conway, P. K. Vogt, A. A. Sartori, J. Scheuermann and D. Neri, Adv. Sci., 2020, 2001970.

56 J. Zhou, W. Shi, L. Li, Q. Gong, X. Wu, X. Li and H. Ma, Anal. Chem., 2016, 88, 4557-4564.
57 W. Mier, C. Kratochwil, J. C. Hassel, F. L. Giesel, B. Beijer, J. W. Babich, M. Friebe, M. Eisenhut, A. Enk and U. Haberkorn, J. Nucl. Med., 2014, 55, 9-14.

58 X. Lai, H. J. Wichers, M. Soler-Lopez and B. W. Dijkstra, Chemistry, 2018, 24, 47-55.

59 G. Zimmermann, Y. Li, U. Rieder, M. Mattarella, D. Neri and J. Scheuermann, ChemBioChem, 2017, 18, 853-857.

60 A. Dal Corso, M. Catalano, A. Schmid, J. Scheuermann and D. Neri, Angew. Chem., Int. Ed., 2018, 57, 17178-17182.

61 M. Catalano, M. Moroglu, P. Balbi, F. Mazzieri, J. Clayton, K. H. Andrews, M. Bigatti, J. Scheuermann, S. J. Conway and D. Neri, ChemMedChem, 2020, 15, 1752-1756.

62 A. Pina, M. Kadri, D. Arosio, A. Dal Corso, J. Coll, C. Gennari and D. Boturyn, Chem. - Eur. J., 2020, 26, 7492-7496.

63 A. Borbély, F. Thoreau, E. Figueras, M. Kadri, J. Coll, D. Boturyn and N. Sewald, Chem. - Eur. J., 2020, 26, 2602-2605.

64 M. Catalano, S. Oehler, L. Prati, N. Favalli, G. Bassi, J. Scheuermann and D. Neri, Anal. Chem., 2020, 92, 10822-10829.

65 S. Vijayasaradhi, B. Bouchard and A. N. Houghton, J. Exp. Med., 1990, 171, 1375-1380.

66 P. Murer, J. D. Kiefer, L. Plüss, M. Matasci, S. L. Blümich, M. Stringhini and D. Neri, J. Invest. Dermatol., 2019, 139, 1339-1348.

67 J. D. Nosanchuk, A. Jeyakumar, A. Ray, E. Revskaya, Z. Jiang, R. A. Bryan, K. J. H. Allen, R. Jiao, M. E. Malo, B. L. Gómez, A. Morgenstern, F. Bruchertseifer, D. Rickles, G. B. Thornton, A. Bowen, A. Casadevall and E. Dadachova, Sci. Rep., 2018, 8, 5466.

68 M. Klein, M. Lotem, T. Peretz, S. T. Zwas, S. Mizrachi, Y. Liberman, R. Chisin, J. Schachter, I. G. Ron, G. Iosilevsky, J. A. Kennedy, E. Revskaya, A. W. de Kater, E. Banaga, V. Klutzaritz, N. Friedmann, E. Galun, G. L. DeNardo, S. J. DeNardo, A. Casadevall, E. Dadachova and G. B. Thornton, $J$ Skin Cancer, 2013, 2013, 1-8.

69 F. Nimmerjahn, Science, 2005, 310, 1510-1512.

70 B. Roulier, B. Pérès and R. Haudecoeur, J. Med. Chem., 2020, DOI: 10.1021/acs.jmedchem.0c00994. 